\title{
ALZHEIMER PATRIMONIAL: GESTIÓN PARTICIPATIVA PARA LA VALORACIÓN Y MEMORIA DEL PATRIMONIO HISTÓRICO INMUEBLE TUMBESINO: EL CASO [PACIENTE) ANTIGUO CABILDO DE TUMBES ${ }^{[*]}$
}

\author{
PATRIMONIAL ALZHEIMER: PARTICIPATORY MANAGEMENT FOR THE VALUATION AND \\ MEMORY OF THE HISTORICAL BUILT HERITAGE OF TUMBES. THE CASE (PATIENT) OLD \\ CABILDO OF TUMBES \\ ERICK BAZÁN TARRILLO ${ }^{[\star \star]}$, ERICK DELGADO BAZÁN ${ }^{(\star \star \star)}$, JULIO RAMÍREZ NÚÑEZ $Z^{(\star \star \star \star)}$ \\ Y CARLOS TORRES MOSQUEIRA ${ }^{[\star \star \star *]}$
}

er_bazta02@hotmail.com

Universidad César Vallejo (Perú) arqerickdelgado18690@gmail.com juliomiguelramirez@hotmail.com carlosrtm@hotmail.com

Fecha de recepción: 28 de octubre de 2018

Fecha de aprobación: 12 de diciembre de 2018

\section{RESUMEN}

Esta investigación se realiza en el contexto del centro histórico de la ciudad de Tumbes (Perú), que presenta en la actualidad casonas en un evidente deterioro, teniendo como objeto de estudio el caso del Antiguo Cabildo. En dicho contexto, se busca conocer y analizar los niveles de reconocimiento y de gestión participativa, a partir de los usos, para la valoración y memoria de este patrimonio histórico cultural, con el fin de identificar la influencia que ejercen en su conservación. El bajo nivel de interés que la sociedad tumbesina demuestra frente al Antiguo Cabildo debe entenderse como si la sociedad pasara a un estado de olvido de sus monumentos históricos, perdiendo incluso la capacidad de reconocerlos, lo que análogamente se define como un Alzheimer patrimonial.

\section{PALABRAS CLAVE}

Antiguo Cabildo; valor patrimonial; gestión participativa; Alzheimer patrimonial

\begin{abstract}
This investigation is carried out in the historic center of the city of Tumbes in Peru, which at present houses masonry in a clear state of disrepair, and has as its focus the old Cabildo. In said context, it seeks to discover and analyze the levels of recognition and participatory management, given different uses, of the valuation and memory of this historical cultural heritage, in order to identify the influence they exert in its conservation. The low level of interest of the citizens of Tumbes in the face of the Cabildo's heritage is equivalent as if society entering a state of oblivion with respect to its monuments, losing even the ability to recognize them, which is analogously defined as heritage Alzheimer.
\end{abstract}

\section{KEYWORDS}

Cabildo de Tumbes; patrimonial value; participative management; heritage Alzheimer

(*) La investigación se desarrolló en 2018 como parte del curso Patrimonio y Arquitectura, dirigido por el MSc. Arq. José Hayakawa en el Doctorado en Arquitectura de la Universidad César Vallejo (UCV).

(**) Arquitecto y máster en Arquitectura por la UCV. Actualmente cursa el doctorado en Arquitectura en la misma universidad. Es docente de la Facultad de Arquitectura de la UCV de Trujillo.

$\left.{ }^{(* * *}\right)$ Arquitecto y máster en Gestión Pública por la UCV, actualmente cursa el doctorado en Arquitectura en la misma universidad. Es docente de la Facultad de Ingeniería Civil y Arquitectura de la Universidad Nacional de San Martín, y de la Facultad de Ingeniería y Ciencia de la Universidad Científica del Perú.

(****) Arquitecto por la Universidad Nacional de La Plata (Argentina). Tiene un máster en Docencia Universitaria y Gestión Educativa por la Universidad Alas Peruanas (UAP), un doctorado en Educación por la Universidad Privada Antenor Orrego (UPAO). Actualmente cursa el doctorado en Arquitectura en la UCV. Es docente en UNP, UAP y UPAO-Piura. $\left({ }^{* * * * *}\right)$ Máster en Docencia Universitaria por la UCV-Trujillo, arquitecto por la Universidad Particular de Chiclayo. Actualmente cursa el doctorado en Arquitectura en la UCV. Es docente de la Facultad de Arquitectura de la UCV-Trujillo y subgerente de Estudios definitivos del Gobierno Regional de La Libertad. 
devenir Vol. 6, N¹1, ENERO - JUNIO 2019, PP. 87-106 - ESTUDIOS I ISSN 2312-7562 I E-ISSN 2616-4949

UnIVERSIDAD NACIONAL DE INGENIERÍA, LIMA

doi: https://doi.org/10.21754/devenir.v6i11.635

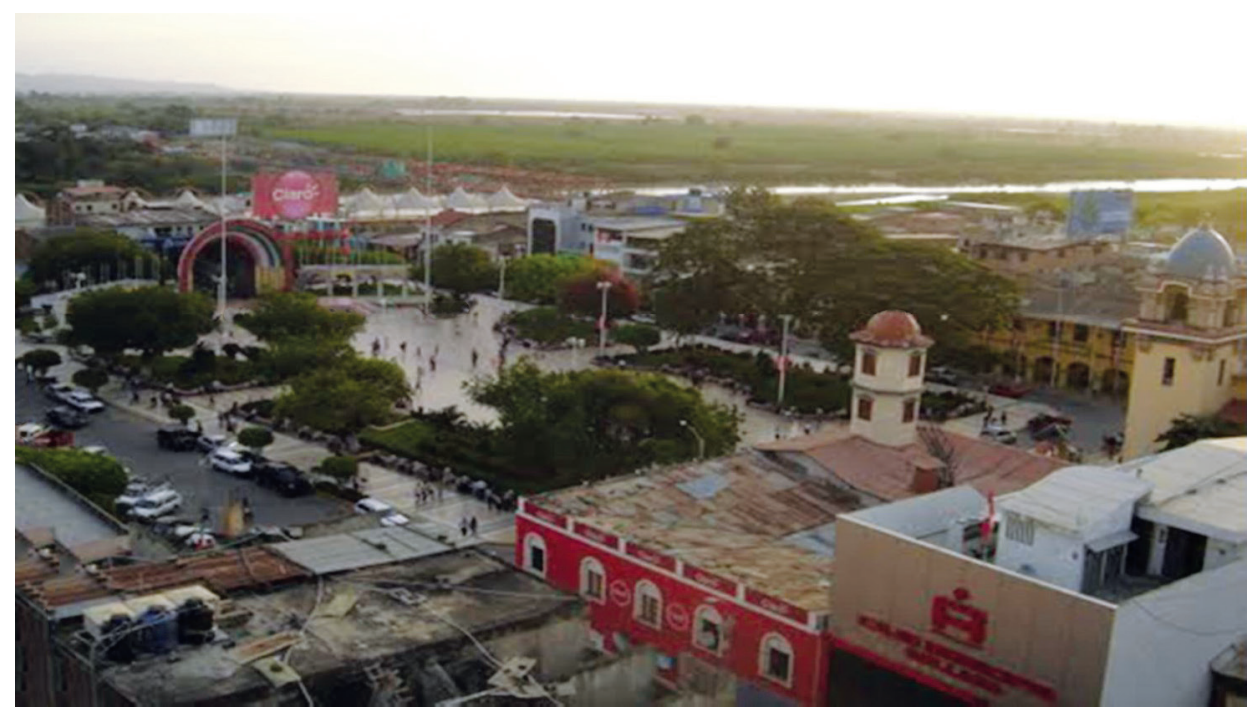

Figura 1. Vista aérea del Centro Histórico de Tumbes. En Expediente Técnico Restauración y Puesta en Valor del antiguo Cabildo de Tumbes Provincia de Tumbes - Departamento de Tumbes, 2014.

Actualmente, las nuevas tecnologías permiten estar conectados a nivel mundial a través de la globalización que, poco a poco, ha generado que las personas fijen su mirada en el "mundo exterior" y olviden su "mundo interior".

A mediados del siglo XVIII, Marx proclamó al mundo burgués estas palabras: "Un fantasma recorre Europa: el comunismo" (como se citó en Bodemer, 1998, p. 54). Del mismo modo, en estos tiempos, la frase que circula entre políticos, empresarios y científicos es la siguiente: "Un fantasma recorre el mundo: la globalización". Sin ir muy lejos, se puede escuchar decir: "Un fantasma recorre el Perú: la indiferencia".

Esta indiferencia ha repercutido en muchos ámbitos, pero principalmente en el patrimonial, ya que pobladores y entes gubernamentales se mantienen al margen de su conservación, y pareciera que se conformaran con papeles, resoluciones y leyes que sin acciones concretas son solo hechos superfluos.

En el Perú, como resultado de esta indiferencia, la población parece estar pasando a un estado de Alzheimer patrimonial. Ello debe entenderse como problemas en la memoria, pensamiento y comportamiento de los involucrados en cuanto a temas vinculados al patrimonio cultural. Por ejemplo, se ha olvidado la Ley N ${ }^{\circ} 28296$, Ley General del Patrimonio Cultural de la Nación, la cual establece políticas nacionales de defensa, protección y promoción de los bienes que lo constituyen. Del mismo modo, el pensar actual se inclina a deshacerse de objetos aparentemente sin valor, lo cual se deja entrever en las conductas de algunos propietarios de bienes inmuebles patrimoniales, que destruyen, humedecen y dañan su infraestructura. Esto es un claro reflejo de la indiferencia hacia la identidad contenida en el patrimonio cultural.

En muchas oportunidades, los habitantes de las ciudades modernas se caracterizan por la rapidez con que pierden la memoria y su capacidad de salvaguardar su patrimonio. Esto se debe a que, mientras se crea arquitectura contemporánea, se atenta contra el patrimonio y se postergan, así, otras capacidades que le permitan edificar un patrimonio nuevo para las futuras generaciones. La inhabilidad se presenta como un síntoma inicial que no permite adquirir nuevos recuerdos; es decir, no se puede conseguir nuevos espacios simbólicos que sean su representación en un futuro, como lo fueron en la ciudad histórica (Hernández, 2017). 
Así, esta investigación tiene por objeto de estudio el centro histórico del departamento de Tumbes (ver Figura 1), el cual en la actualidad alberga casonas en evidente estado de deterioro. Para ello, se pretende analizar la gestión participativa del patrimonio histórico cultural del Centro Histórico de Tumbes, en relación a su valoración y memoria.

El objetivo de esta investigación involucra identificar y difundir el valor patrimonial en la categoría de uso, formal y simbólico, del Antiguo Cabildo de Tumbes. Se busca conocer, y analizar los niveles de reconocimiento y de usos participativos para la valoración y memoria del patrimonio histórico cultural del Centro Histórico de Tumbes, con el fin de identificar la influencia que ejercen en su conservación.

En este estudio, se ha considerado los valores patrimoniales en sus tres categorías: uso, formal y simbólico. A partir de ello, se plantea indagar respecto de la identidad de los pobladores en relación a la valoración que ellos le atribuyen al patrimonio. Para ello, se tomará como base los planteamientos de McCarthy, quien afirma que el reflejo de los valores que una comunidad hereda del edificio es lo que le proporciona el sentido patrimonial (2012, como se citó en Villamón, 2017).

Respecto a la categoría de uso, se preguntó en la encuesta sobre el uso que los pobladores consideran más relevante para el Antiguo Cabildo; por ejemplo, si consideran que debería funcionar actualmente como un centro financiero (valor económico), un centro educativo de talleres o cultural (valor educativo), una sede de administración pública (valor funcional), un centro de reuniones vecinales (valor social), un museo o una sala de exposiciones (valor científico).

En cuanto a la categoría simbólica, se indagó sobre la percepción de los pobladores acerca del valor del inmueble, a saber, si está vinculado con la historia que representa (valor histórico), los años de antigüedad que posee (valor de existencia), las técnicas constructivas empleadas (valor de legado), su presencia en los recuerdos de su infancia o juventud (valor de identidad), o porque ahí funcionó el antiguo registro civil, la Municipalidad y la biblioteca (valor de imagen).

De igual manera, abarcando los tres valores de la categoría formal, se planteó un hecho hipotético para conocer la percepción del poblador y despertar sus sentidos: se les cuestionó sobre una posible demolición del Antiguo Cabildo de Tumbes para construir un moderno edificio en su lugar.

Por otra parte, se realizaron preguntas orientadas a identificar el sentido de afinidad de la población con los bienes culturales, así como a saber si es que estarían dispuestos a participar en la reconstrucción de los mismos. Para ello, se realizó un muestreo por conveniencia, seleccionando el Antiguo Cabildo de Tumbes, y se empleó una metodología de carácter mixto; para la recopilación de datos, se utilizó el cruce de fuentes documentales primarias, y técnicas de investigación como entrevistas, encuestas y la observación, empleando cuestionarios y fichas de observación.

Una delimitación importante en este estudio es que se basa en datos que rigen al último periodo del gobierno local, entre 2014 y 2018. Documentación, estudios y otros anteriores a estos años no se incluyen entre los datos que ayudan a medir el nivel de reconocimiento, y gestión participativa en cuanto a la valoración y memoria del patrimonio histórico del Antiguo Cabildo de Tumbes.

\section{Conceptos}

Para comprender mejor algunos conceptos de este artículo, se empezará abordando el término Alzheimer. Según Peña (1999), se trata de una enfermedad neurodegenerativa que avanza de manera progresiva, la cual se caracteriza por la pérdida de la memoria y porque altera el comportamiento del paciente, lo cual, a su vez, repercute significati- 
devenir Vol. 6, N¹1, ENERO- JUNIO 2019, PP. 87-106 - ESTUDIOS | ISSN 2312-7562 I E-ISSN 2616-4949

UNIVERSIDAD NACIONAL DE INGENIERÍA, LIMA

doi: https://doi.org/10.21754/devenir.v6i11.635

Tabla 1. Clasificación de los valores patrimoniales para un bien inmueble

\begin{tabular}{|c|c|c|c|}
\hline & Categoría & Valor Patrimonial & Descripción \\
\hline \multirow{5}{*}{ De uso } & \multirow{5}{*}{$\begin{array}{l}\text { Satisface necesidades concretas, } \\
\text { que pueden ser individuales o } \\
\text { colectivas. }\end{array}$} & Económico & $\begin{array}{l}\text { Generación de ingresos económicos por el mismo hecho de ser patri- } \\
\text { monio, o por el hecho de conservarlo }\end{array}$ \\
\hline & & Funcional & $\begin{array}{l}\text { Considerar el uso original del bien o algun uso funcional compatible } \\
\text { con su carácter }\end{array}$ \\
\hline & & Educativo & $\begin{array}{l}\text { Posesión de elementos culturales e históricos que favorecen a la } \\
\text { educación y/o al turismo, y permiten la concientización sobre cultura } \\
\text { e historia }\end{array}$ \\
\hline & & Social & $\begin{array}{l}\text { Permitir la interaccion social entre comunidad y gobierno local, y } \\
\text { establecer vinculos de identidad social y cultural }\end{array}$ \\
\hline & & Científico & $\begin{array}{l}\text { Por las características del bien, obtención de información que contri- } \\
\text { buya al incremento del conocimiento humano }\end{array}$ \\
\hline \multirow{3}{*}{ Formal } & \multirow{3}{*}{$\begin{array}{l}\text { Evalúa el bien por la atracción } \\
\text { que despierta en los sentidos, en } \\
\text { cuanto al placer estético, rareza y } \\
\text { apariencia exótica. }{ }^{1}\end{array}$} & $\begin{array}{l}\text { Técnico o } \\
\text { artístico }\end{array}$ & $\begin{array}{l}\text { Relevancia del diseño del bien cultural, por su concepción, hechura, y } \\
\text { las técnicas, estructuras y funciones empleadas }\end{array}$ \\
\hline & & De originalidad & $\begin{array}{l}\text { Carácter original, es decir, representativo y singular en cuanto a otros } \\
\text { elementos de su tiempo, región, uso y estilo }\end{array}$ \\
\hline & & De conjunto & Integración del bien al paisaje, como unidad y como conjunto \\
\hline \multirow{5}{*}{$\begin{array}{l}\text { Simbólico o } \\
\text { comunicativo }\end{array}$} & \multirow{5}{*}{$\begin{array}{l}\text { Posee presencia sustitutiva de } \\
\text { alguien o algo, siendo un medio de } \\
\text { trasferencia de ideas y contenido, } \\
\text { comunicando un significado. }{ }^{1}\end{array}$} & Histórico & $\begin{array}{l}\text { Carácter de testigo de los sucesos acontecidos en un momento deter- } \\
\text { minado de la historia }\end{array}$ \\
\hline & & De existencia & $\begin{array}{l}\text { Por su simple existencia, generación de goce y disfrute por parte de la } \\
\text { comunidad, se haga uso o no de este }\end{array}$ \\
\hline & & De legado & Transmisión de información y valores para las generaciones futuras \\
\hline & & De identidad & $\begin{array}{l}\text { Establecimiento de vínculos de reconocimiento social, cultural y reli- } \\
\text { gioso, de forma que proporciona identidad a la sociedad y al individuo }\end{array}$ \\
\hline & & De imagen & $\begin{array}{l}\text { Configuración de una imagen retrospectiva y significativa de las } \\
\text { razones que dieron lugar a la evolución histórica }\end{array}$ \\
\hline
\end{tabular}

Elaboración propia sobre la base de Hayakawa (como se citó en Marsia, 2016, p. 102) y Ballart y I tresserras (2001).

1. Ballart et al., 2001

vamente en su entorno familiar y social. Sin embargo, para emplear esta noción en el contexto de este artículo, debe sumarse a este primer concepto el término patrimonio. Así, lo que corresponde es entender a qué se quiere hacer referencia con el concepto Alzheimer patrimonial: se trata de la pérdida de la memoria y la capacidad mental de identificar, valorar, y salvaguardar el patrimonio histórico mueble e inmueble.

Otro de los conceptos que aquí se emplearán es patrimonio histórico inmueble. Según Prats (1997, como se citó en García, 2011), originalmente se entendía por patrimonio 
solo a aquellas propiedades susceptibles de ser poseídas por un individuo o una familia; sin embargo, actualmente, también se emplea para referirse tanto a bienes como a costumbres, las cuales se trasmiten entre generaciones, pues se reconoce en ellos valores y un carácter de propiedad colectiva.

El Instituto Nacional de Cultura (INC) (2015) refiere que el patrimonio está compuesto por bienes materiales e inmateriales que nuestros antepasados han dejado a lo largo de la historia, mediante los cuales se ha ido forjando una identidad como Nación; así mismo, lo divide en categorías como patrimonio mueble y patrimonio inmueble.

Sin embargo, para esclarecer la definición aislada de patrimonio, cabe preguntarse qué se podría precisar como patrimonio histórico. Para esto, se debe remontar al siglo XIX, cuando se añaden dos características al concepto de patrimonio. La primera, que se trata de un objeto de testimonio; la segunda, que el bien histórico es un objeto de estudio, "que tuvo como finalidad, con ayuda de la Arqueología, entender las sociedades del pasado, para así dejar de buscar únicamente piezas de valor y empezar a usar los restos del pasado en estudios e interpretaciones" (Casado, 2009, p. 4). En ese sentido, el INC (2015) divide el patrimonio en dos categorías: patrimonio arqueológico (si son bienes provenientes de la época prehispánica) y patrimonio histórico (si se trata de bienes fechados a partir de la llegada de los españoles).

Por otra parte, Hayakawa (2015) refiere que, valor patrimonial es aquella cualidad que poseen los bienes muebles e inmuebles, por la cual estos pueden llegar a ser estimables; es decir, adquieren un valor a partir de la estimación que le pueden dar diversos grupos humanos y que, a su vez, estos pueden estimarlos en diferentes índoles y magnitudes.

Ballart y Tresserras (2001) parten de la idea de que el patrimonio obtiene valor mediante las cualidades y virtudes que contiene, así como por la utilidad que puede tener, es decir, su valor como recurso. Para ello, estos autores ponderan tres grandes categorías convencionales: valor de uso, valor de forma y valor simbólico. Para este estudio en adelante se ha considerado las tres categorías antes mencionadas con el fin de conocer, identificar y difundir el valor patrimonial entre los pobladores de Tumbes (ver Tabla 1).

En cuanto a gestión participativa, Pérez J. (2006) refiere que esta es un modelo organizado y fundamentado en la comunicación entre los pobladores y las autoridades (gobierno local). Por ello, resulta fundamental promover y gestionar actividades en pos de la conservación del patrimonio no solo como elemento observable, sino como elemento utilizable y funcional.

Para la UNESCO (2014), la gestión adecuada para el desarrollo del patrimonio exige una perspectiva orientada a la sostenibilidad y que esta, a su vez, pueda alcanzar un razonable equilibrio entre obtener beneficios del patrimonio hoy y salvaguardar su "frágil riqueza" para las generaciones venideras.

\section{Historia de Tumbes}

La ciudad de Tumbes, ubicada en la parte norte del Perú (ver Figura 2), es sobreabundante en historia. Nace a la memoria colectiva como ciudad en su fundación por Francisco Pizarro, en 1532. Tumbes fue la primera ciudad fundada por los españoles en el Perú. Sirvió, en sus inicios, como cabecera de puente en esa región para el descubrimiento y conquista de nuevas tierras al sur de América. Así, la ciudad fue creciendo y comenzó a formar parte de la memoria histórica del Perú, mientras atravesaba un lento y constante proceso de conformación de su arquitectura y sus primigenios espacios urbanos, todo en medio de un exuberante paisaje natural.

En la ciudad de Tumbes (ver Figura 3), los espacios urbanos son la memoria de dicha urbe, en la cual se han acumulado distintas capas como si fueran mil historias de su

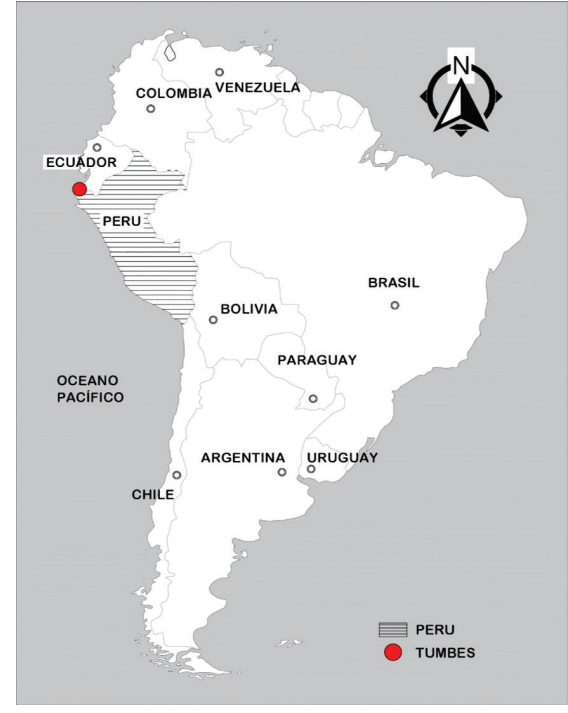

Figura 2. Ubicación de Perú y localización del departamento de Tumbes. Elaboración propia, 2018. 
devenir Vol.6, N¹1, ENERO - JUNIO 2019, PP. 87-106 - ESTUDIOS | ISSN 2312-7562 | E-ISSN 2616-4949

UNIVERSIDAD NACIONAL DE INGENIERÍ, LIMA

doi: https://doi.org/10.21754/devenir.v6i11.635

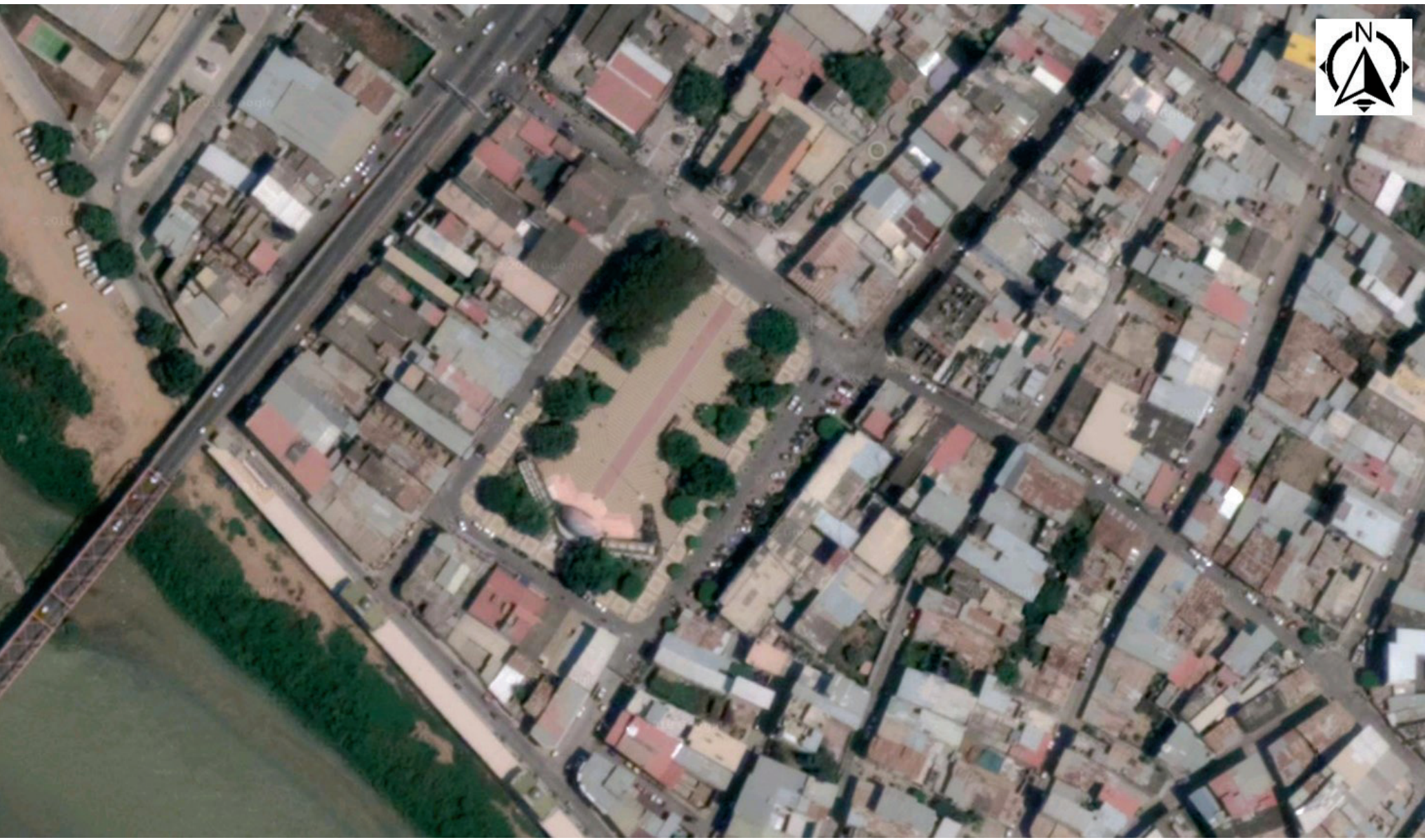

Figura 3. Vista aérea de la ciudad de Tumbes. Google Earth, 2018.

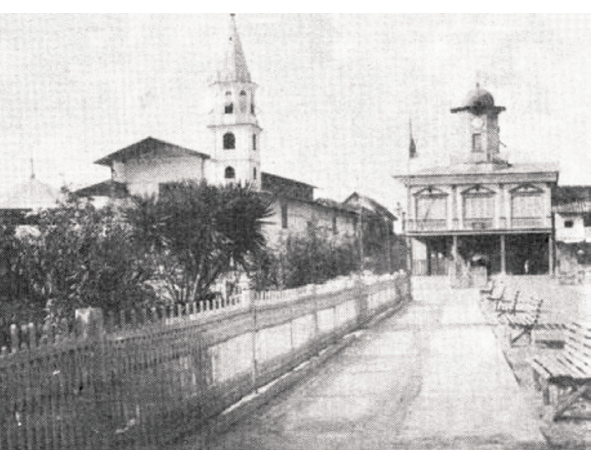

Figura 4. Vista frontal del Antiguo Cabildo de Tumbes en 1925. Informe técnico del estado situacional del antiguo cabildo de Tumbes, 2011 evolución desde el pasado. Lo que puede verse hoy, como en todo hecho urbano, es una suerte de libro abierto que narra los acontecimientos que, poco a poco, fueron construyendo la memoria de la ciudad.

En ella se puede, se puede observar las huellas entremezcladas del pasado y el presente. Por ejemplo, a través de sus edificios, como el Antiguo Cabildo de Tumbes (ver Figura 4), que alberga en sí información valiosa sobre las técnicas constructivas que se emplearon, su configuración de espacios, los usos del espacio, y la historia y evolución del mismo:

De hecho, las formas de los objetos que nos rodean tienen significados y no erramos al decir que, están alrededor de nosotros como una sociedad muda e inmóvil, aunque no hablen, les comprendemos, ya que tienen un sentido que desciframos de manera familiar. (Halbwachs, 1968 , p. 218)

La ciudad de Tumbes, rodeada de terrenos agrícolas, se extiende a lo largo de la carretera Panamericana Norte, y tiene como límite, al sur, el río del mismo nombre. Sus habitantes, como guías, pueden explicar al visitante el proceso de evolución e historia de la ciudad. Esta, al ser recorrida, va contando escenas de sus interesantes cambios y transformaciones históricas, mutaciones que muchas veces son el reflejo de los cambios de carácter social, geográfico, político y económico que ha atravesado la ciudad a lo largo del tiempo. Del mismo modo, su paisaje y espacio urbano fueron paulatinamente cambiados o su arquitectura destruida por lo frágil de sus edificaciones, cons- 
truidas de material de la región, como caña de Guayaquil chancada, madera hualtaco y bambú. Lastimosamente, solo algunas han sobrevivido hasta la actualidad, entre ellas el Antiguo Cabildo de Tumbes (ver Figuras 5 y 6). Escasos documentos quedan de los primeros esbozos de la ciudad, de sus cambios y metamorfosis, pues dicho proceso fue poco o nada documentado.

En los relatos orales de los propios habitantes, se cuenta sobre las periódicas inundaciones del río Tumbes, el único navegable de toda la costa del Perú, que año a año inundaba todo el centro histórico de la ciudad (ver Figura 7), con lo que cambiaban las costumbres de sus habitantes, quienes, acostumbrados a este acontecimiento periódico que tenía lugar todos los años durante los meses de enero, febrero y marzo, salían en sus canoas desde sus viviendas tipo palafito en la década del 1920 para hacer las compras al mercado o hacer vida social.

La llegada del ferrocarril en la década de 1930 cambió el paisaje de la principal avenida de la ciudad. Le otorgó un nuevo sentido de espacialidad, acústica y movimiento a esta arteria importante de la ciudad, y modificó su aspecto urbano. Muchas de estas intervenciones urbanas son narradas por los habitantes, quienes construyeron sus calles, avenidas y plazas, y cuentan historias particulares con significados muy arraigados que ya son parte de la memoria colectiva.

Es así que la calle, como lugar o ámbito del vehículo y también del peatón, contiene historias. Por ejemplo, la calle de Mercaderes, actual calle Huáscar, era la antigua arteria comercial de Tumbes; la intersección de las avenidas Grau y Huáscar, en forma de cruz, tiene la intención de recordar a Miguel Grau en la epopeya del combate de Angamos ante la flota chilena; las calles paralelas Francisco Pizarro, Diego de Almagro y Hernando de Luque fueron nombradas en memoria de los tres socios de la conquista, debido a que Tumbes fue la primera cuidad con la que contactaron; por último, los nombres de las calles del sector oeste de la ciudad recuerdan los territorios usurpados por Chile durante la guerra del Pacifico: Tacna, Arica, Tarapacá y Tarata.

La mayoría de las calles antiguas de Tumbes, a diferencias de otras zonas del norte del Perú, tienen una característica espacial urbana muy especial: cuentan con veredas cubiertas por el avance de las viviendas en el segundo piso, lo cual las hace más frescas y acogedoras al estar protegidas del sol inclemente y de las lluvias torrenciales. Se trata de una respuesta sensible a los eventos atmosféricos, así como de verdaderos espacios de transición entre lo público y lo privado.

Las manzanas son bloques rectangulares de poco fondo, que hacen más eficiente el uso del espacio residencial, y siguen la irregular topografía del terreno. Así, se recrean calles con regulares pendientes y perspectivas distintas, los cuales enriquecen el paisaje. Por otra parte, los paseos comerciales como elementos vertebradores y catalizadores del centro de la ciudad se recuerdan como el paseo de la concordia, la paz y la tensión bélica con el vecino país del Ecuador, preñado de elementos alegóricos de la cultura ancestral y que remata en un elemento que simboliza la concordia y paz entre los dos pueblos.

Su plaza principal, que cuenta con especies vegetales propias de la región, tiene como papel fundamental la organización de la ciudad: es el centro social, el espacio socializador e integrador, no solo por su posición central, sino también por su rol cívico, religioso y comercial, pues está rodeada de elementos urbano-arquitectónicos como la recova comercial, la iglesia y la Municipalidad. El perímetro de la plaza principal presenta una recova o vereda cubierta, como espacio intermedio apacible y fresco. Lamentablemente, estas expresiones de respuesta al medio actual cada vez más se van perdiendo. Dentro de poco, solo quedarán las imágenes y recuerdos de lo que en su momento fue un espacio público agradable y fresco.

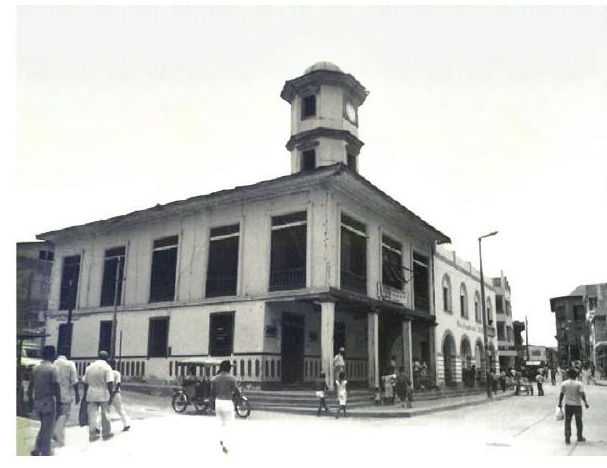

Figura 5. Vista esquinada del Antiguo Cabildo de Tumbes en 1976. Archivo Loayza, DPHCR Ministerio de Cultura. Como se citó en Informe técnico del estado situacional del antiguo cabildo de Tumbes, 2011

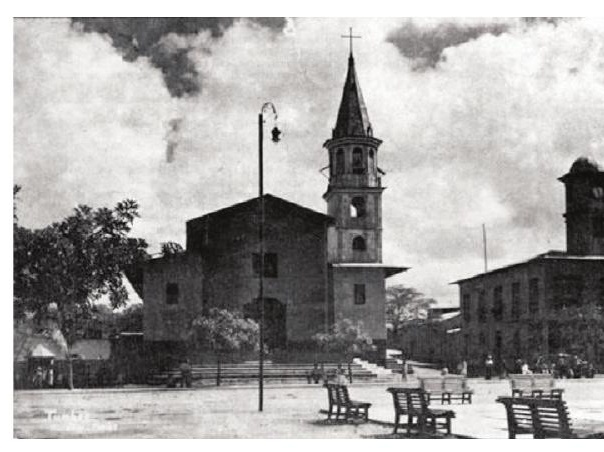

Figura 6. Vista parcial del antiguo cabildo de Tumbes en 1925. Informe técnico del estado situacional del antiguo cabildo de Tumbes, 2011.

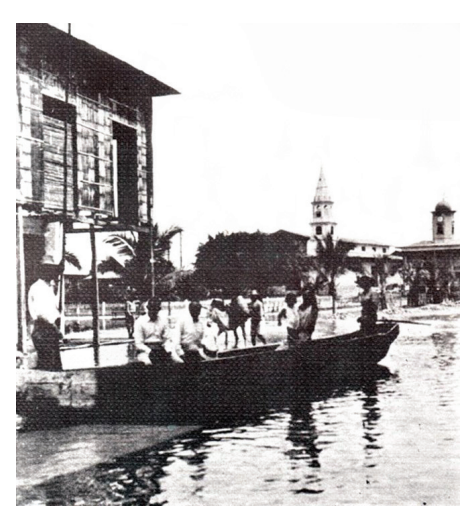

Figura 7. Vista de la población transportándose en canoa en Tumbes antiguo. Recuperado de http://amanecertumbesino.blogspot.com/2013/12/ tumbes-antiguo_7.html 
devenir Vol. 6, N¹1, ENERO- JUNIO 2019, PP. 87-106 - ESTUDIOS | ISSN 2312-7562 I E-ISSN 2616-4949

UnIVERSIDAD NACIONAL DE INGENIERÍA, LIMA

doi: https://doi.org/10.21754/devenir.v6i11.635

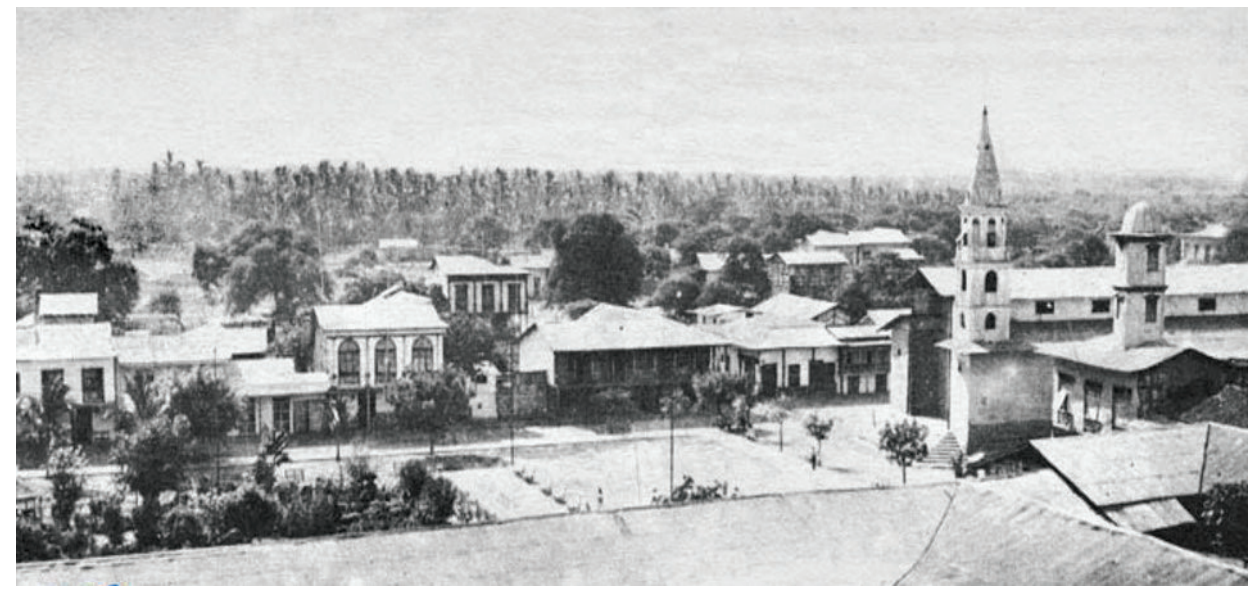

Figura 8. Vista de la Plaza de Armas del antiguo Tumbes. Recuperado de https://www.iperu.org/historia-de-tumbes-peru

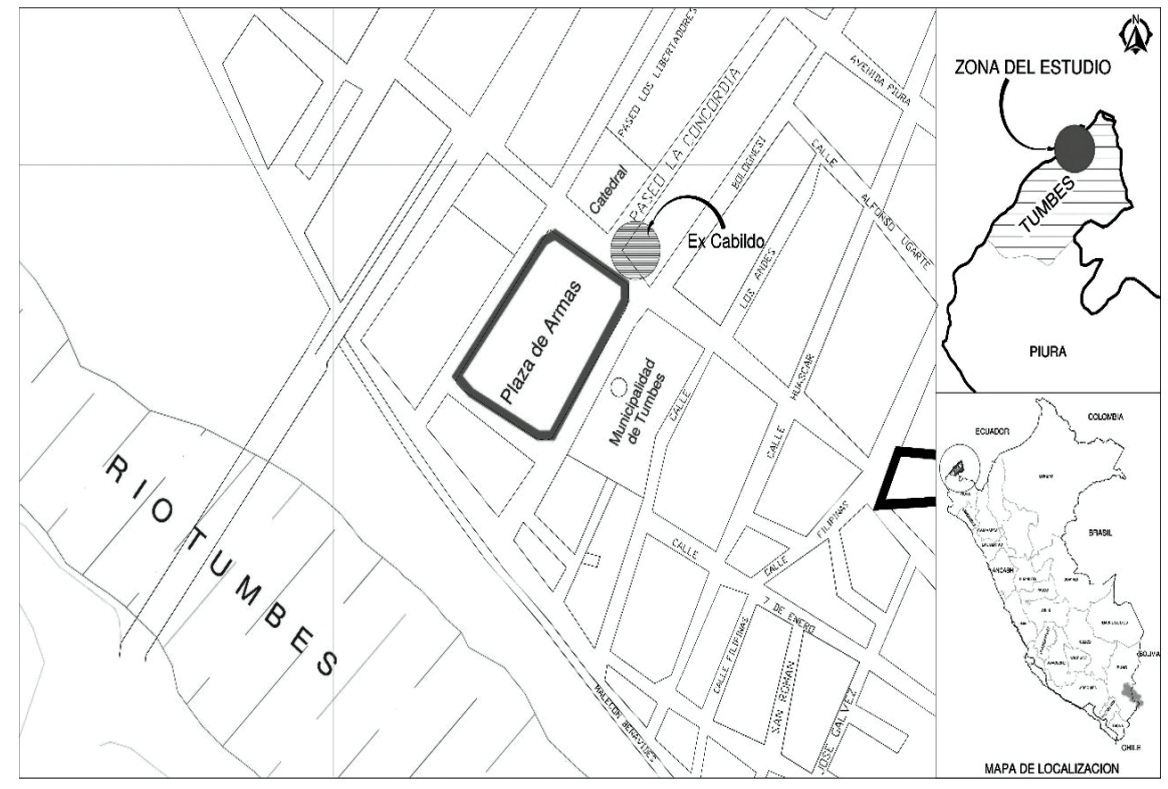

Figura 9. Ubicación y localización del Antiguo Cabildo de Tumbes. Elaboración propia, 2018.

En la década de los años 60, las viviendas en la ciudad de Tumbes tenían una particular codificación, vinculada a las actividades que se desarrollaban en su interior. En las fachadas, en la parte superior de las ventanas y puertas, podían encontrarse figuras caladas, que representaban, mediante alegorías, el tipo de actividad económica que realizaba la familia que allí habitaba.

Con el devenir de los años, se han incorporado nuevas figuras caladas, que no guardan relación con la labor o actividad económica que realiza la familia. Estas figuras caladas carecen de significado y no consideran la historia ni las tradiciones, lo cual da origen a nuevas expresiones culturales, ajenas y, en muchos casos, totalmente descontextualizadas.

En este espacio público (ver Figura 8), saturado de memorias y experiencias biográficas, los cuales aparecen plasmados en sus pisos y paredes a través de múltiples formas, olores y colores, alimentan el recuerdo cotidiano de sus ciudadanos que comparten recuerdos comunes. En palabras de Mumford (1938), "los monumentos, edificios, calles, avenidas, plazas y parques no son apenas lo que queda en el presente de las ciu- 


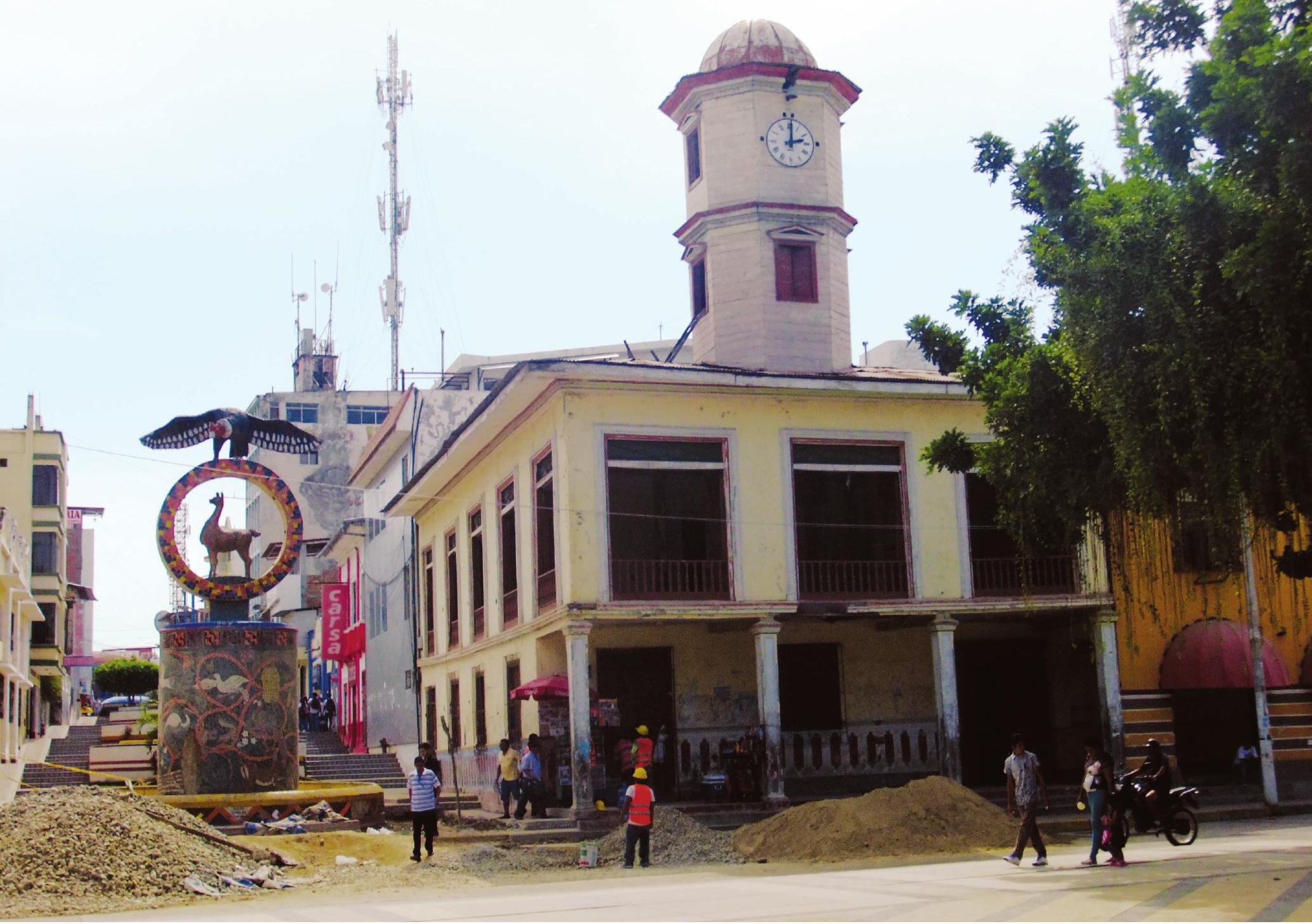

dades del pasado, sino que evocan hechos históricos, pues fueron su escenario, como lo continúan siendo de los actuales" (p. 4).

Figura 10. Antiguo Cabildo de Tumbes. Archivo personal del autor, 2018.

La ciudad, al igual que ciertos organismos vivos, hereda distintos grados de organización que cambian, mutan y evolucionan, los cuales apoyados en códigos una vez identificados y catalogados formarían parte de esa herencia mental colectiva, comprendiendo de manera más racional el proceso mediante el cual la memoria urbana se transmite de generación en generación.

\section{Reconociendo el Patrimonio}

Las viviendas más antiguas y mejor conservadas datan de la época republicana. Sin embargo, debido al avance del progreso y de la especulación inmobiliaria, son pocas las que permanecen en pie. En el interior de estas casonas antiguas, se encuentran espacios domésticos muy confortables, producto de más de 200 años de prueba y error, lo cual se manifiesta en la frescura de sus ambientes, fruto del control climático natural logrado gracias a la altura de su espacios, puertas y ventanas, con control de ruidos, asoleamiento, deslumbramiento y control de insectos. Estas casonas antiguas, que son un ejemplo de control medioambiental, se encuentran en peligro de desaparecer. Muy pocas se han inventariado y protegido, a pesar de que son también parte de la historia y de la memoria colectiva, por ser cuna de personalidades y de acontecimientos históricos.

El local del Antiguo Cabildo de Tumbes se encuentra ubicado al noreste de la Plaza de Armas de Tumbes. Por el Norte, colinda con el paseo Concordia y la catedral de Tum- 
devenir Vol. 6, N¹1, ENERO- JUNIO 2019, PP. 87-106 - ESTUDIOS | ISSN 2312-7562 | E-ISSN 2616-4949

UnIVERSIDAD NACIONAL DE INGEEIERÍA, LIMA

doi: https://doi.org/10.21754/devenir.v6i11.635

Figura 11. Plano primer nivel del Antiguo Cabildo. En Proyecto de Inversión Pública Restauración y Puesta en Valor del Ex Cabildo de Tumbes. Provincia de Tumbes - Departamento de Tumbes, por Municipalidad Provincial de Tumbes, 2014.

Figura 12. Plano segundo nivel del Antiguo Cabildo. En Proyecto de Inversión Pública Restauración y Puesta en Valor del Ex Cabildo de Tumbes. Provincia de Tumbes - Departamento de Tumbes, por Municipalidad Provincial de Tumbes, 2014.

Figura 13. Elevación lateral del Antiguo Cabildo. En Proyecto de Inversión Pública Restauración y Puesta en Valor del Ex Cabildo de Tumbes. Provincia de Tumbes - Departamento de Tumbes, por Municipalidad Provincial de Tumbes, 2014.

Figura 14. Elevación frontal del Antiguo Cabildo. En Proyecto de Inversión Pública Restauración y Puesta en Valor del Ex Cabildo de Tumbes. Provincia de Tumbes - Departamento de Tumbes, por Municipalidad Provincial de Tumbes, 2014.

Figura 15. Corte general de la torre del Antiguo Cabildo. En Proyecto de Inversión Pública Restauración y Puesta en Valor del Ex Cabildo de Tumbes. Provincia de Tumbes - Departamento de Tumbes, por Municipalidad Provincial de Tumbes, 2014.
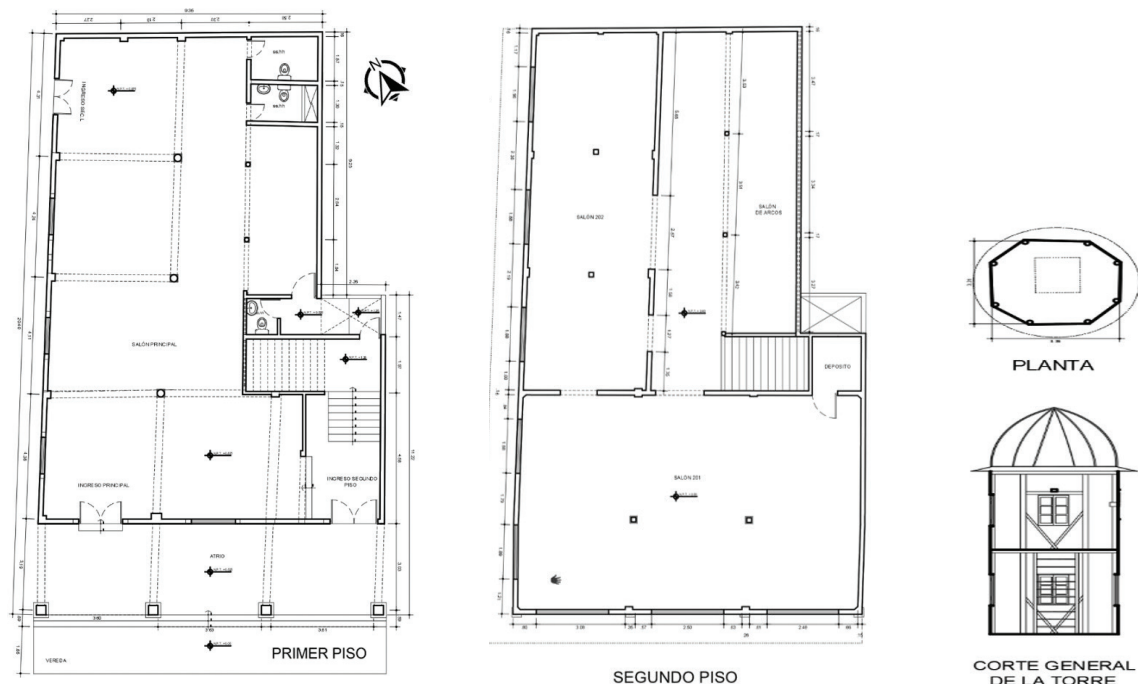

PLANTA

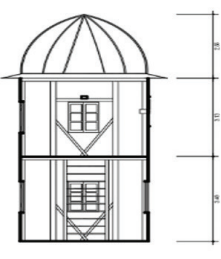
CORTE GENERAL
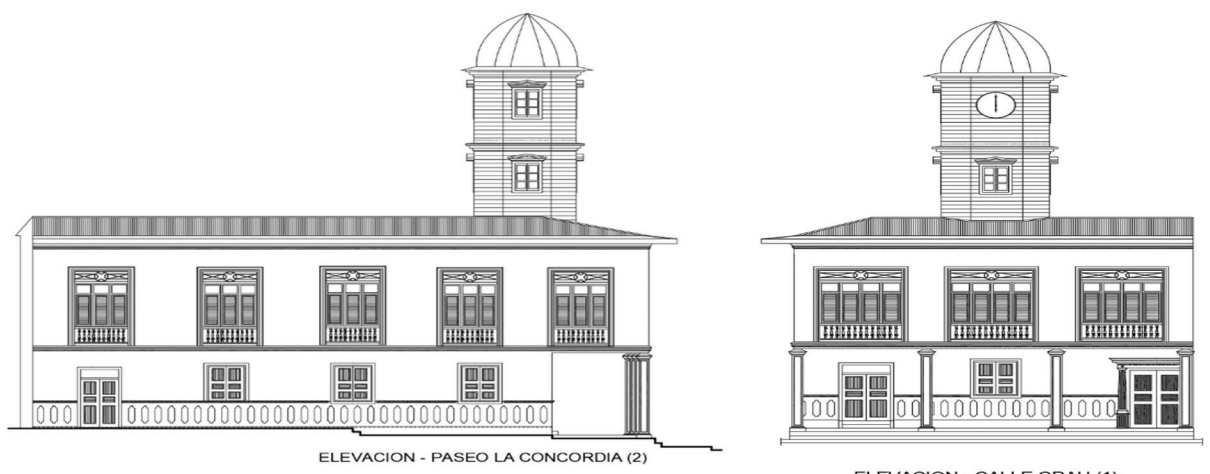

ELEVACION - CALLE GRAU (1)

bes; por el Sur, con la Municipalidad Provincial de Tumbes; por el Este, con comercios locales; $y$, por el Oeste, con la Plaza de Armas (ver Figura 9). Distinguido desde los inicios del siglo XIX como el Antiguo Cabildo de Tumbes, está ubicado precisamente en el jr. Grau 301 en esquina con San Martín 112.

El Antiguo Cabildo de Tumbes (ver Figura 10) fue conformado por orden real el 4 de julio de 1529, con el nombramiento del regidor don García de Salcedo. En esta fecha, la reina doña Juana, a nombre del emperador Carlos V, firmó en la ciudad de Toledo la Cédula Real. Se trata de una edificación, de origen colonial, que representa la arquitectura civil y pública de la época. Hasta el año 1911, fue sede del Cabildo o Municipio de Tumbes; sin embargo, con el paso de los años, también se usó como Biblioteca Municipal, y posterior a eso, entre usos y desusos, también albergó negocios locales.

Esta edificación se desarrolla en dos niveles (ver Figuras 11 y 12) sobre los cuales se asienta una torre de dos cuerpos (ver Figuras 13, 14 y 15), que alberga el primer reloj público que tuvo Tumbes. El inmueble posee un pórtico de estilo neoclásico y ventanales de madera. En el primer nivel, posee una planta libre; en el segundo nivel (ver Figura 16), los espacios son cerrados. Está edificado con columnas y vigas de madera, muros y techos de caña revestida con barro y yeso (ver Figuras 17,18 y 19). Con el pasar del tiempo, debido a diversos sucesos climatológicos, las condiciones estructurales y constructivas de la edificación se han ido deteriorando. Además, la falta de mantenimiento ha sido un silencioso colaborador de tal degradación. 

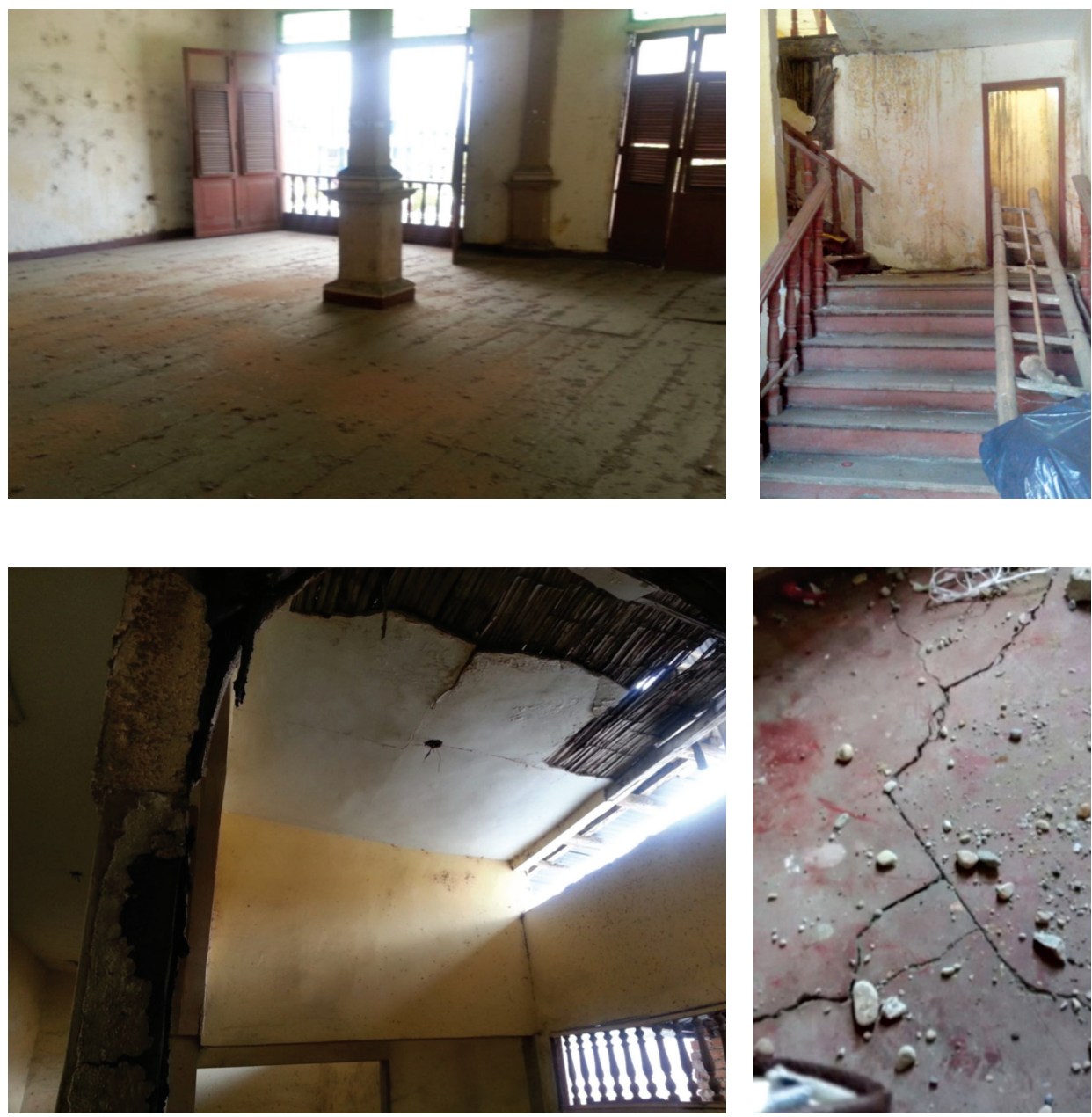

El Antiguo Cabildo de Tumbes forma parte importante de la historia de Tumbes y de sus pobladores, que deberían consignar un grado alto de reconocimiento del mismo. Por ello, para determinar el grado de dicho reconocimiento de parte de los habitantes, se aplicó una encuesta ${ }^{1}$, en la cual las dos primeras preguntas estaban basadas en la prueba de reconocimiento de siluetas progresivas ${ }^{2}$. La primera pregunta mostraba parte de la imagen de la torre del Antiguo Cabildo de Tumbes; la segunda, parte del monumento del paseo Concordia.

En la primera pregunta, el $92.3 \%$ de los encuestados reconoció la imagen, y señaló que se trataba del Antiguo Cabildo de Tumbes (ver Figura 20). Estos resultados dejan claro que existe un alto índice de reconocimiento del inmueble, así como el hecho de que se aprecia la identidad cultural del lugar. Por otra parte, en la segunda pregunta, el $96.2 \%$ pudo identificar con facilidad la imagen de la estatua del paseo Concordia (ver
Figura 16. Vista del segundo nivel del Antiguo Cabildo. En Proyecto de Inversión Pública Restauración y Puesta en Valor del Ex Cabildo de Tumbes. Provincia de Tumbes - Departamento de Tumbes, por Municipalidad Provincial de Tumbes, 2014

Figura 17. Escalera que conduce al segundo nivel. En Proyecto de Inversión Pública Restauración y Puesta en Valor del Ex Cabildo de Tumbes. Provincia de Tumbes - Departamento de Tumbes, por Municipalidad Provincial de Tumbes, 2014.

Figura 18. Techo en mal estado. En Proyecto de Inversión Pública Restauración y Puesta en Valor del Ex Cabildo de Tumbes. Provincia de Tumbes - Departamento de Tumbes, por Municipalidad Provincial de Tumbes, 2014.

Figura 19. Estado del piso. En Proyecto de Inversión Pública Restauración y Puesta en Valor del Ex Cabildo de Tumbes. Provincia de Tumbes - Departamento de Tumbes, por Municipalidad Provincial de Tumbes, 2014.

\footnotetext{
1. Se seleccionó una muestra de 26 pobladores, utilizando un método de muestreo no probabilístico, por conveniencia, intencional y premeditada, tomando como criterio priorizar personas quienes han trabajado y han vivido cerca del ex cabildo de Tumbes, y que además son conocedores de su historia, ya que, en esta investigación, no se busca generalizar resultados de toda la población, sino enfocarse en dar profundidad y calidad a las preguntas de investigación y entrevistas. La muestra está limitada por tiempo y espacio, pero podría ampliarse posteriormente.

2. Test de cribado. Consta de cuatro pruebas de reconocimiento de objetos, y de percepción espacial y siluetas progresivas. Se aplicó la última.
} 
devenir Vol. 6, N¹1, ENERO- JUNIO 2019, PP. 87-106 - ESTUDIOS | ISSN 2312-7562 I E-ISSN 2616-4949

UNIVERSIDAD NACIONAL DE INGENIERÍ, LIMA.

doi: https://doi.org/10.21754/devenir.v6i11.635

Reconoce la imagen de la torre del Antiguo Cabildo

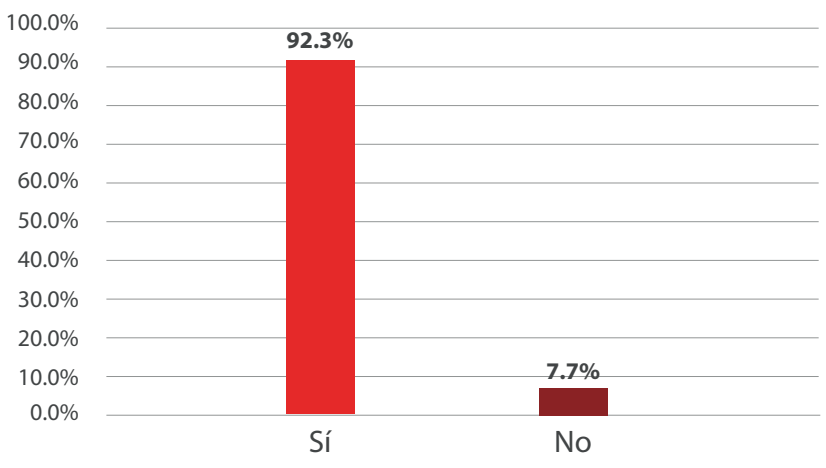

Figura 20. Porcentaje de personas que reconocen al Antiguo Cabildo. Elaboración propia sobre la base de encuestas, 2018.

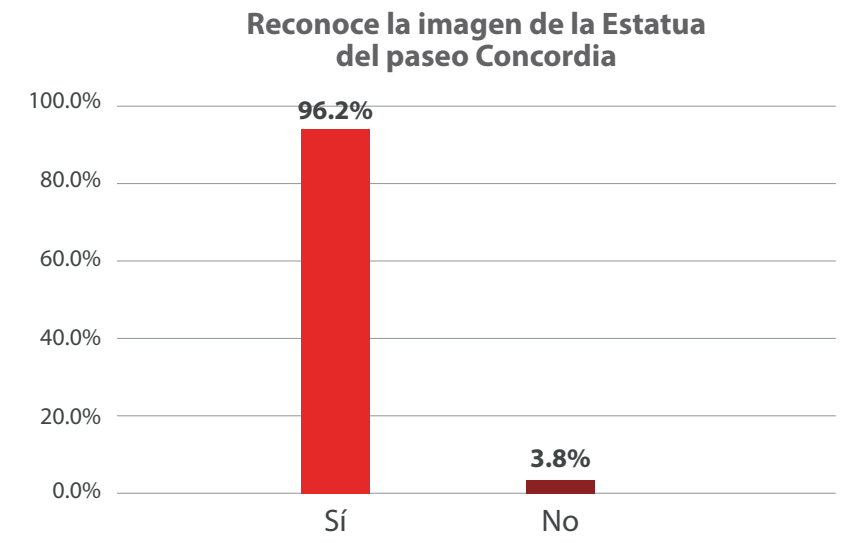

Figura 21. Porcentaje de personas que reconocen la estatua del paseo Concordia. Elaboración propia sobre la base de encuestas, 2018

Figura 21). Estos resultados muestran que existe un mayor nivel de reconocimiento por la estatua del paseo Concordia que por el Antiguo Cabildo de Tumbes.

El reconocimiento está ligado muy cercanamente con factores de identidad:

...es una pena que no se cuiden estas reliquias de casas, tanto tiempo abandonadas; hay tanta historia para contar de cada una de ellas, para contarles a los niños porque es parte de la historia de Tumbes. No podemos ser tan mezquinos con nuestros recuerdos y perder nuestra identidad. (R. Moran, 38 años, comunicación personal, 27 de julio de 2018)

El poder reconocer un bien debe significar poder identificarlo como parte de la historia (los hechos pasados), la historia actual (la manera de vivir en el presente) y la historia futura (para las generaciones venideras).

Además de indagar sobre el reconocimiento personal, se buscó conocer si la población poseía algún referente respecto del reconocimiento legal que posee el Antiguo Cabildo de Tumbes. Solo para el $30.8 \%$ de los encuestados, el Antiguo Cabildo de Tumbes sí está reconocido como patrimonio cultural (ver Figura 22).

Cabe resaltar que, el 7 de junio de 2016, la comisión de Cultura del Congreso de la República Peruana aprobó el Proyecto de Ley 3159, que declara de interés nacional y necesidad pública la restauración, conservación y puesta en valor del Antiguo Cabildo de Tumbes. Del mismo modo, se sabe que con Resolución Directoral Nacional № 0789, en Lima, del 30 de octubre de 2003, el Antiguo Cabildo de Tumbes ha sido nombrado Monumento Integrante del Patrimonio Cultural de la Nación.

\section{Valor patrimonial}

En cuanto al valor del bien o a la estimación que los pobladores tienen sobre el Antiguo Cabildo de Tumbes, es posible citar a Hayakawa (2015), que refiere que el valor patrimonial es la cualidad que posee un bien, por la cual este puede llegar a ser estimable; es decir, adquiere un valor a partir de la estimación que le pueden dar diversos grupos humanos a partir de una característica determinada. Para determinar dicho aspecto en esta investigación, se formuló una pregunta en relación a reconocer el valor del Antiguo Cabildo de Tumbes, además de requerir que los encuestados indiquen algunos referentes de por qué lo consideraban valioso.

El $84.6 \%$, de los encuestados considera valioso el Antiguo Cabildo de Tumbes (ver Figura 23). Para indagar en las razones que determinaron la respuesta a dicha interrogante, se tomó como población total a los 22 pobladores que indicaron que sí les 


\section{El Antiguo Cabildo es considerado Patrimonio} Cultural de la Nación

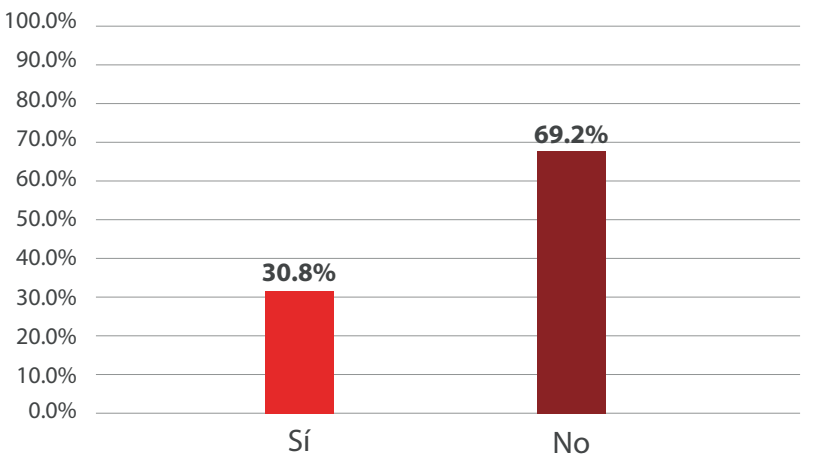

Figura 22. Porcentaje de personas que afirman que el Antiguo Cabildo está considerado como patrimonio. Elaboración propia sobre la base de encuestas, 2018.
Considera que actualmente es valioso el Antiguo Cabildo de Tumbes

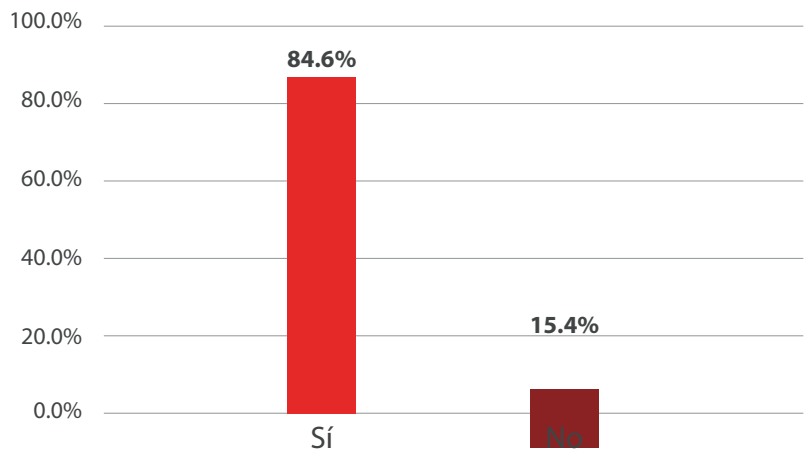

Figura 23. Porcentaje de personas que consideran valioso al Antiguo Cabildo. Elaboración propia sobre la base de encuestas, 2018.

parecía valioso y se obtuvo los siguientes resultados: en cuanto a su valoración por antigüedad el porcentaje asciende a $12.2 \%$; por su historia, a $41.5 \%$; por sus técnicas constructivas, a $14.6 \%$; por la valoración personal de recuerdos y vivencias, a $17.1 \%$; por los usos que tenía, $14.6 \%$ (ver Figura 24).

En los resultados, resalta claramente el valor histórico como factor fundamental para la valoración del bien. En consecuencia, tener un patrimonio cultural y valorarlo debe significar darle vida y "resaltar un sentido utilitario al patrimonio... es estratégico que para que este 'invento social' adquiera 'sentido social', la sociedad debe percibirlo útil y necesario" (Hayakawa, 2010).

En ese sentido, el Antiguo Cabildo de Tumbes, al no ser utilizado durante cerca de 20 años por decisiones políticas locales y falta de financiamiento, a pesar de ser un ícono representativo de la ciudad, se está destruyendo físicamente. Esta situación, con el tiempo, generará que nuevas generaciones no lo tengan en cuenta, pues no se les inculca la importancia de valorar y conservar este patrimonio, como manifiesta un poblador tumbesino:

....aparte que este tipo de valores no nos han enseñado en el colegio, al menos a mí no me las han enseñado. Me enseñaron a valorar nuestros símbolos patrios, escudo, bandera, el himno nacional, pero de conservar y respetar estos edificios por su antigüedad y su historia nada... Yo he aprendido a apreciarlos porque al menos he salido de Tumbes, he vivido y algo he leído sobre este tema. Pienso que defenderíamos y apreciaríamos más estos edificios si los conociéramos más en profundidad. (H. Jiménez, 68 años, comunicación personal, 27 de julio de 2018).

La conservación de los bienes es uno de los temas relevantes en todo edificio patrimonial. Por esta razón, se planteó un caso hipotético en la encuesta, orientado a conocer el porcentaje de aceptación de los pobladores (ver Figura 25): el $84.6 \%$ de los encuestados indicó que no se encuentra de acuerdo con que se construya un nuevo edificio moderno en lugar del Antiguo Cabildo de Tumbes. Estos resultados coinciden con los testimonios recogidos:

¿Cómo vamos a permitir demolerlo? Eso es parte del patrimonio de Tumbes, es como una herencia y habría que cuidarlo, darle mantenimiento periódicamente. Aparte de encontrarse en el centro de Tumbes, el edificio no es feo, es bonito, tiene sus cosas, no creo que existan personas que pretendan demolerlo. El edificio forma parte de mi juventud, en época de lluvias el edificio te protegía,... aparte en ese edificio tantas personas que se han casado, tantos cosas e eventos históricos que se han dado en ese edificio: ha soportado dos terremotos, ha sido visitado por presidentes en diferentes épocas, ... tiene mucha historia, no es cualquier edificio. (H. Jiménez, 68 años, comunicación personal, 27 de julio de 2018) 
devenir Vol. 6, N¹1, ENERO- JUNIO 2019, PP. 87-106 - ESTUDIOS | ISSN 2312-7562 | E-ISSN 2616-4949

UNIVERSIDAD NACIONAL DE INGENIERÍA, LIMA

doi: https://doi.org/10.21754/devenir.v6i11.635

Razón por la cual es valioso el Antiguo Cabildo de Tumbes

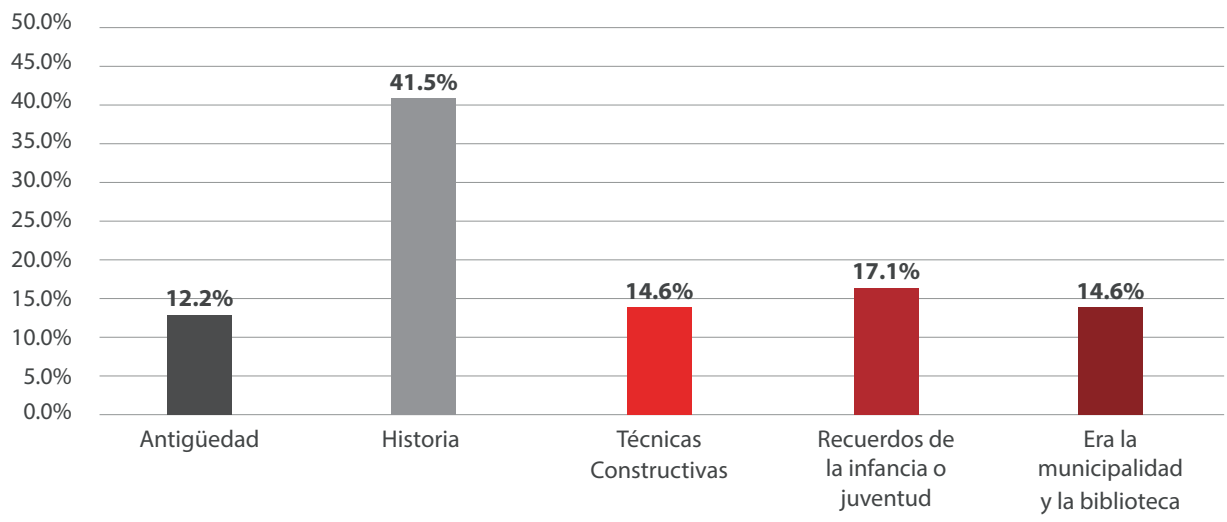

Figura 24. Porcentaje de personas que indican razón por la cual es valioso el Antiguo Cabildo. Elaboración propia sobre la base de encuestas, 2018.

Está de acuerdo con que se construya un edificio moderno en el lugar del Antiguo Cabildo

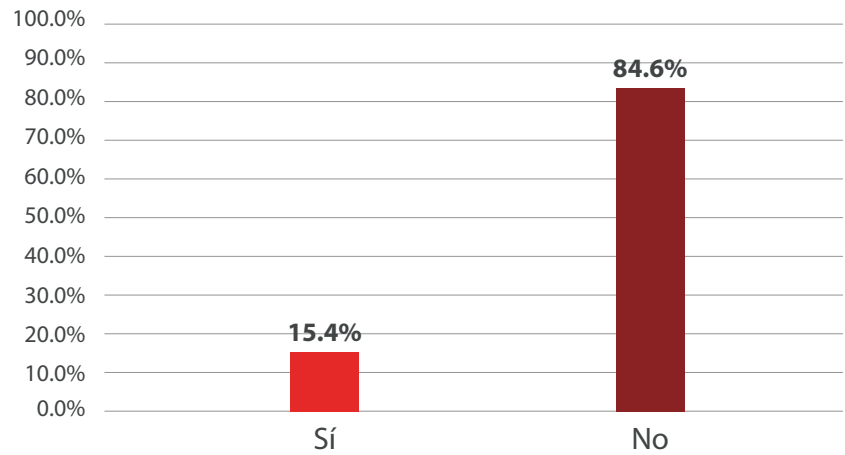

Figura 25. Porcentaje de personas de acuerdo en construir un moderno edificio en reemplazo del Antiguo Cabildo. Elaboración propia sobre la base de encuestas, 2018.

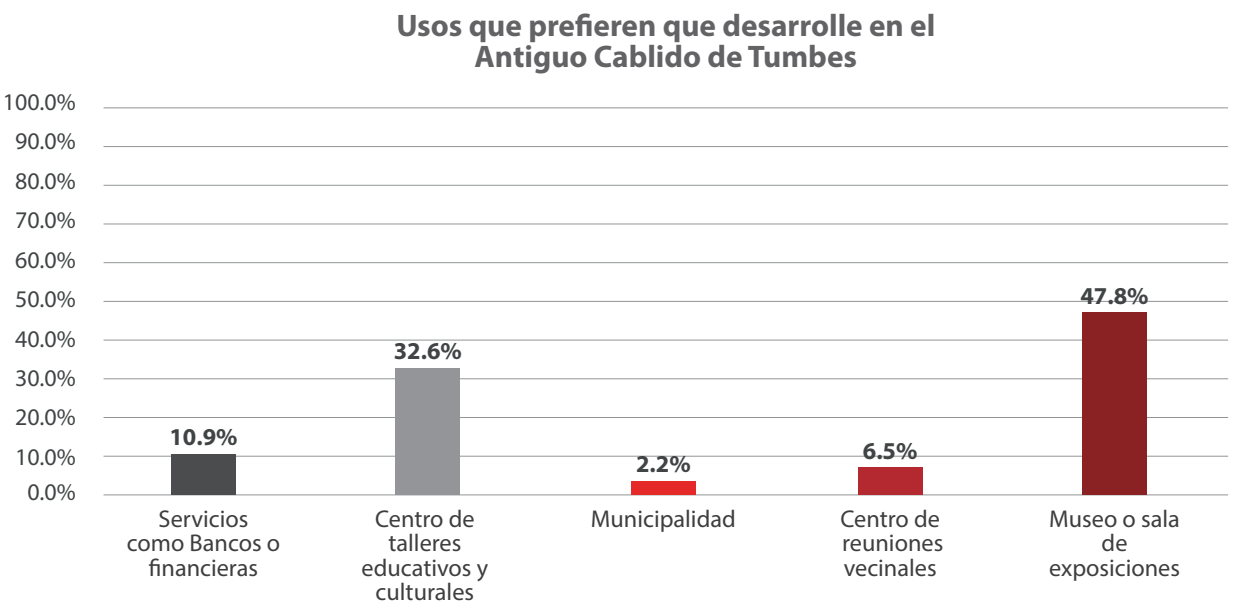

Figura 26. Usos que los pobladores prefieren se desarrolle en el Antiguo Cabildo. Elaboración propia sobre la base de encuestas, 2018. 
La gente desconoce, hay mucho olvido y desdén, pero de lo que sí puedo estar seguro es que, si lo demolieran, todo el mundo pegaría el grito al cielo, y pedirían la cabeza del alcalde. (R. Campaña, 70 años, comunicación personal, 27 de julio de 2018)

El valor de uso del bien debe ser particular o colectivo, como refiere Ballart (2001), pero además debe tener cierta afinidad en sus usos iniciales y los actuales. Por ende, para abordar este asunto, se realizaron preguntas basadas en los valores de categoría de uso que establecen Hayakawa et al. (2001, como se citó en Montañez, 2016). Los resultados se exponen a continuación.

El $47.8 \%$ de encuestados prefieren que se desarrolle un uso como museo o sala de exposiciones; el $32.6 \%$, como un centro de talleres educativos y culturales; el $10.9 \%$ se inclina por usos como bancos o financieras; un $6.5 \%$ prefiere el uso como centro de reuniones vecinales; $y$, finalmente, el $2.2 \%$ prefiere el uso de Municipalidad (ver Figura 26).

Cabe recalcar que es importante que la población tumbesina y sus autoridades integren este bien a su vida cotidiana, es decir, que bien se le asigne un uso, sea administrativo, educativo o cultural, que permita su conservación con el pasar de los años. Esto se puede comprobar en el presente estudio: cuando el cabildo fue utilizado como biblioteca, desde 1999 hasta 2000, aproximadamente, se mantuvo en un buen estado de conservación. Sin embargo, después que dejó de funcionar como tal, permaneció prácticamente abandonado; es como que si la sociedad pasara a un estado de Alzheimer patrimonial. Ya que la sociedad no le da importancia, el monumento va perdiendo de manera progresiva el valor que tiene y con el tiempo cae en el olvido, tal como se manifiesta en el siguiente testimonio:

...yo vivía a pocas cuadras de la plaza de Tumbes, y el reloj es el que daba la hora en todo el cercado de Tumbes en ese entonces, en el primer piso funcionaba la oficina de telégrafos, registro civil, rentas y otros, que no recuerdo. (R. Torres, 56 años, comunicación personal, 27 de julio de 2018).

\section{Gestión participativa}

Por último, en cuanto a la gestión participativa, es necesario analizar la participación ciudadana, así como la participación gubernamental en cuanto a intervención con el fin de conservar el patrimonio. El papel de los gobiernos en el campo cultural varía en cada país. Existen distintos modelos de intervención, en los que cambia el papel asignado a las instituciones públicas y privadas. En países como Francia y España, la estructura administrativa está basada en la preeminencia de la iniciativa gubernamental sobre la iniciativa de la población. Por otra parte, existe el modelo británico, basado en la iniciativa y solicitud de los pobladores. En ese caso, el gobierno local se ocupa de asignar fondos públicos, y gestionar directamente los presupuestos y las políticas culturales, a partir de la iniciativa y solicitud de los ciudadanos. En Estados Unidos, existe la idea de servicio público, pero tiene una historia muy diferente a la de Europa.

Allí, el voluntarismo y la filantropía gozan de una larga tradición y, como consecuencia, el servicio público se identifica con las intervenciones privadas y generalmente individuales en la vida de la comunidad, y no propiamente con el Estado. Desde la política fiscal, se apoya este modelo y se articulan incentivos vinculados a la exención de impuestos: el Gobierno opta por no recaudar dinero a cambio de que las empresas realicen donaciones a organizaciones no lucrativas. Ello explica el gran número de instituciones culturales privadas y las grandes cantidades de dinero destinadas a proyectos culturales, que se manejan por parte de organizaciones privadas no lucrativas de todos los tamaños. El modelo norteamericano concuerda con algunas manifestaciones recogidas en Tumbes mediante entrevistas, pues coincide en el uso privado de las edificaciones patrimoniales como medio para conservarlas: 
devenir Vol. 6, N¹1, ENERO- JUNIO 2019, PP. 87-106 - ESTUDIOS | ISSN 2312-7562 I E-ISSN 2616-4949

UNIVERSIDAD NACIONAL DE INGENIERÍA, LIMA

doi: https://doi.org/10.21754/devenir.v6i11.635

Pobladores dispuestos a trabajar en la restauración y conservación en el Antiguo Cabildo de Tumbes

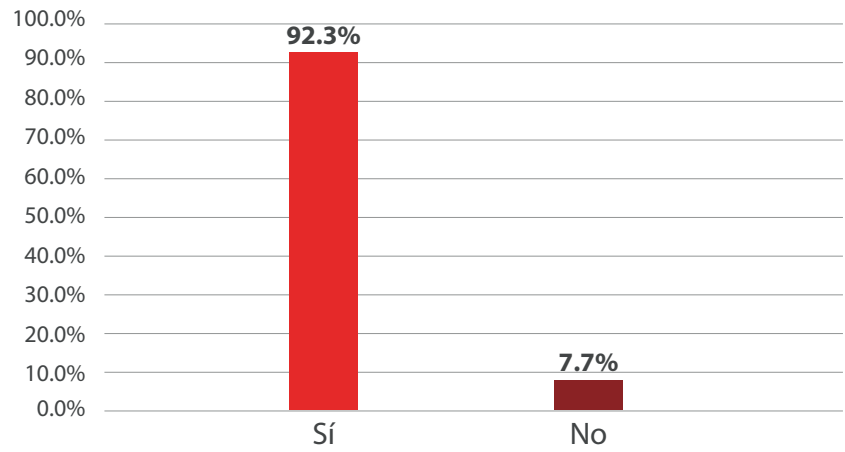

Figura 27. Porcentaje de pobladores dispuestos a trabajar en la restauración y conservación en el Antiguo Cabildo de Tumbes. Elaboración propia sobre la base de encuestas, 2018.

Tabla 2. Nuevos retos de las actividades para la gestión del patrimonio cultural

\begin{tabular}{|c|c|c|}
\hline Retos & Actividades & Descripción \\
\hline \multirow{4}{*}{$\begin{array}{l}\text { Renovación de la } \\
\text { gestión pública en } \\
\text { cultura }\end{array}$} & $\begin{array}{l}\text { El ciudadano como } \\
\text { protagonista }\end{array}$ & Administración está al servicio del ciudadano \\
\hline & $\begin{array}{l}\text { Fomentar la coope- } \\
\text { ración }\end{array}$ & $\begin{array}{l}\text { Trabajo entre la administración pública y las } \\
\text { organizaciones culturales }\end{array}$ \\
\hline & Flexibilidad & Estructuras, equipamientos y métodos de trabajo \\
\hline & Formación continua & $\begin{array}{l}\text { Profesionales que se formen en conocimiento de } \\
\text { tecnologías para la mejorar niveles de gestión }\end{array}$ \\
\hline \multirow{3}{*}{$\begin{array}{l}\text { Dar vida a los equi- } \\
\text { pamientos creados }\end{array}$} & Consumo cultural & De los ciudadanos \\
\hline & $\begin{array}{l}\text { Capacidad para hacer } \\
\text { frente a las demandas }\end{array}$ & La capacidad de los equipamientos \\
\hline & $\begin{array}{l}\text { Fomentar la partici- } \\
\text { pación ciudadana }\end{array}$ & La población cercana a cada equipamiento \\
\hline \multirow{2}{*}{$\begin{array}{l}\text { Estar abiertos a los } \\
\text { nuevos ámbitos de } \\
\text { cultura }\end{array}$} & Prácticas culturales & $\begin{array}{l}\text { Población que difunde manifestaciones cultura- } \\
\text { les tradicionales }\end{array}$ \\
\hline & $\begin{array}{l}\text { Prácticas cuasicul- } \\
\text { turales }\end{array}$ & $\begin{array}{l}\text { Población que difunde manifestaciones cultura- } \\
\text { les modernas }\end{array}$ \\
\hline \multirow{2}{*}{ Mejorar relaciones } & Cultura - Educación & $\begin{array}{l}\text { Los centros educativos como generadores de } \\
\text { cultura }\end{array}$ \\
\hline & $\begin{array}{l}\text { Cultura - Medios de } \\
\text { comunicación }\end{array}$ & $\begin{array}{l}\text { Los medios de comunicación como promovedo- } \\
\text { res de cultura }\end{array}$ \\
\hline
\end{tabular}

Elaboración propia, basado en Mikel Etxebarria (como citó en Hayakawa, 2010) 
ALZHEIMER PATRIMONIAL: GESTIÓN PARTICIPATIVA PARA LA VALORACIÓN Y MEMORIA DEL PATRIMONIO HISTÓRICO INMUEBLE TUMBESINO:

El CASO (PACIENTE) ANTIGUO CABILDO DE TUMBES

Erick Bazán Tarrillo, Erick Delgado Bazán, Julio Ramírez Nuñez y Carlos Torres Mosqueira

doi: https://doi.org/10.21754/devenir.v6i11.635

Tabla 3. Principios para la gestión del patrimonio cultural

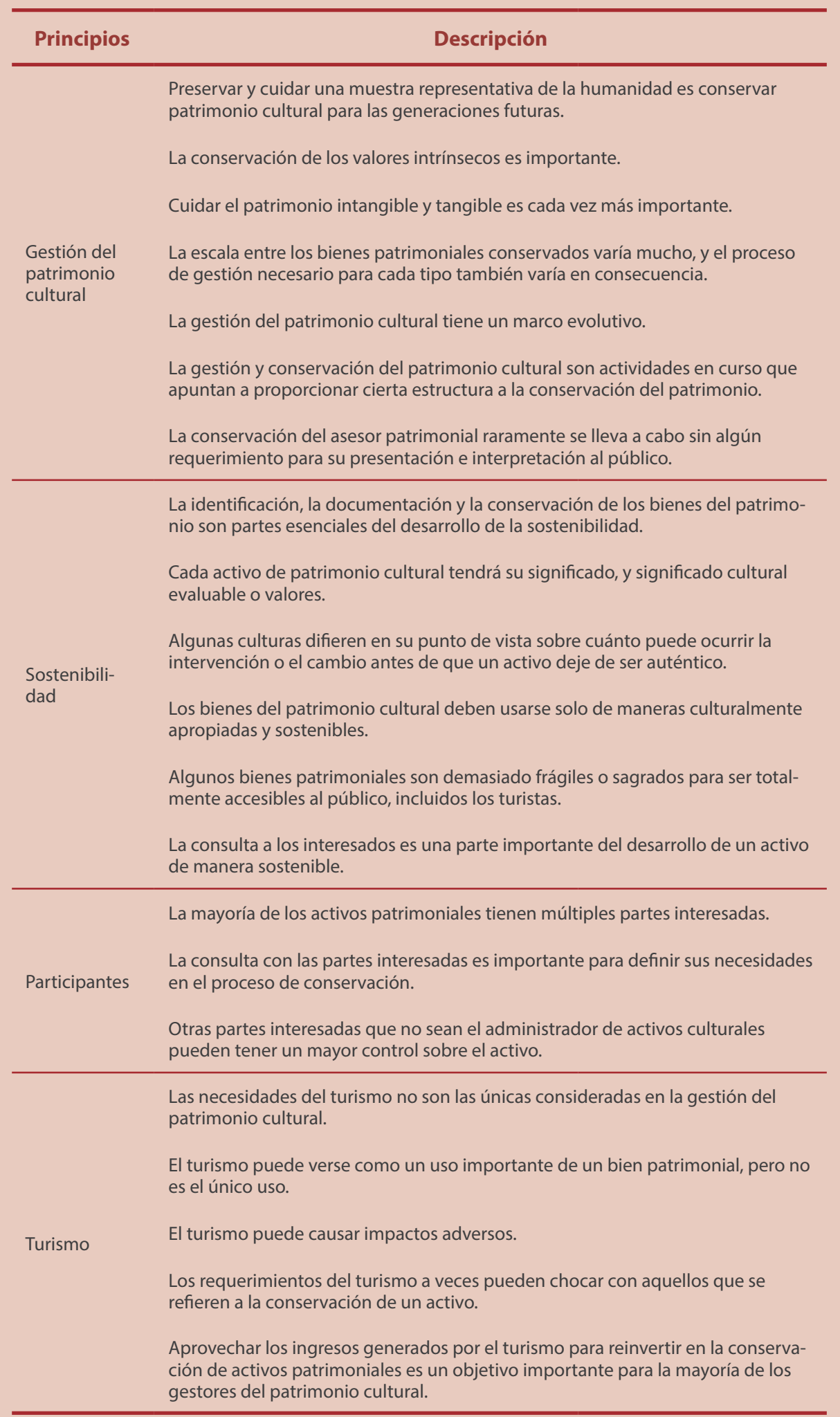

Nota: Traducción propia (Como se citó en Hayakawa, 2010) 
devenir Vol. 6, N¹1, ENERO- JUNIO 2019, PP. 87-106 - ESTUDIOS | ISSN 2312-7562 | E-ISSN 2616-4949

UnIVERSIDAD NACIONAL DE INGENIERÍA, LIMA

doi: https://doi.org/10.21754/devenir.v6i11.635

Bueno, yo he vivido en Trujillo mucho tiempo y allá estos edificios los conservan mediante convenios con entidades bancarias para darles un uso y mantenimiento como una de las formas de conservarlos. Pienso que uniendo esfuerzos desde la parte pública y privada se podría conservar algunas de las casonas antiguas, que ya quedan muy pocas y sería una pena que se pierdan. (E. Santillán, 68 años, comunicación personal, 27 de julio de 2018)

Sin embargo, debería desarrollarse un modelo de gestión institucional de abajo a arriba. En otras palabras, lo importante no es tanto quién hace, sino qué debe hacerse. En ese sentido, se planteó una última pregunta en el cuestionario en relación al grado de participación que consideran deseable. El $92.3 \%$ de la población se mostró dispuesta a ser partícipe de la conservación del patrimonio (ver Figura 27).

Ante estos resultados, es necesario establecer nuevos retos en la actualidad para mejorar la gestión del uso del patrimonio cultural, ante lo cual, acorde a lo planteado por Mikel Etxebarria (ver Tabla 2), se debe plantear retos como renovar la gestión pública, dar vida a los equipamientos, estar atentos a nuevos ámbitos de cultura y mejorar relaciones, todo esto con el fin de que la población sea partícipe en la recuperación del patrimonio.

La Municipalidad Provincial de Tumbes, en el intento de conservar y restaurar el Antiguo Cabildo de Tumbes para el beneficio de la población, en el año 2014, elaboró el Proyecto de Inversión Pública (PIP) Restauración y Puesta en Valor del Antiguo Cabildo de Tumbes - Provincia de Tumbes - Departamento de Tumbes. En el PIP, se precisa una matriz de involucrados, entre los que se considera a la población beneficiada, a la Municipalidad Provincial de Tumbes y al Ministerio de Cultura.

Uno de los autores interesados de valorar el Antiguo Cabildo de Tumbes fue el excongresista Manuel Merino de Lama, quien sustentó el proyecto de Ley 3159, el cual "declara de interés nacional y necesidad pública la restauración, conservación y puesta de valor del antiguo cabildo de Tumbes". Dicho proyecto fue difundido mediante una nota periodística en el diario local El Correo el 9 de junio de 2016. A pesar de que exista interés de parte de algunas autoridades, a la fecha no se han realizado las acciones necesarias para evitar su olvido. Sigue, pues, deteriorándose y con tendencia a desaparecer:

La falta de visión que tienen las autoridades es un problema. Es por desconocimiento, ignorancia con respecto a las cosas e historias que estábamos hablando ...y desidia e ineptitud, falta de visión de nuestras autoridades. (H. Jiménez, 68 años, comunicación personal, 27 de julio de 2018)

Para promover una gestión del patrimonio más adecuada, esta debe fundamentarse en algunos principios, tal y como indica Hayakawa (2010), quien citando a Mckecher y Ducros (2002), establece principios de gestión en cuanto a la conservación, además de hacer hincapié en la importancia de la sostenibilidad, es decir, identificar, documentar y conservar el bien, así como consultar a los involucrados respecto del proceso. Cabe recalcar que el turismo no es el único uso que se puede plantear para el patrimonio recuperado. Debe plantearse usos que con el pasar de los años permitan conservar el patrimonio de forma que quede como legado para las generaciones futuras (ver Tabla 3).

\section{Conclusiones}

La preservación y el cuidado del Antiguo Cabildo de Tumbes deben ser entendidos como muestra representativa del acervo cultural patrimonial, que significa mantener muchos valores intrínsecos importantes, tanto tangibles como intangibles.

La historia del Antiguo Cabildo ha demostrado que, durante el uso que se le asignó como biblioteca, este permaneció en buenas condiciones. Así mismo, la población refiere que se le debería asignar un uso en la actualidad, con el fin de recuperar este patrimonio cultural. 
La gestión, en el caso del Antiguo Cabildo de Tumbes, ha dado como resultado rescatarlo del olvido, de la anomia de los distintos actores de la ciudad, a través de distintas actividades, dentro de un marco evolutivo que se inició en la década de los años 80 y 90, etapa que culminó en 2003, cuando fue declarado integrante del Patrimonio Cultural de la Nación por el INC. Desde 2014, se cuenta en la Municipalidad Provincial de Tumbes con un PIP para su recuperación y restauración, pues este bien patrimonial posee elementos culturales e históricos que favorecen la educación y el turismo, y permite, con ello, concientizar a la población sobre la cultura e historia de Tumbes. Puede operar como un transmisor de información y valores para las generaciones futuras, y permitir establecer vínculos de reconocimiento social, cultural y religioso de forma que proporcione identidad a la sociedad y al individuo.

Existe interés de la población por participar en la mejora del Antiguo Cabildo, lo que debe ser un punto de partida para la recuperación de este bien inmueble y a su vez una motivación para el gobierno local en promover la gestión participativa en su localidad.

Dentro de su marco de sostenibilidad, se prevé involucrar de forma efectiva la participación de las partes interesadas, dada la tendencia actual de abandono. Si bien es cierto que el turismo puede causar efectos favorables y a la vez adversos, por uso y usufructo del bien, se generaría ingresos para reinvertir en su recuperación, objetivo central para los gestores del patrimonio cultural. Con la recuperación del Antiguo Cabildo de Tumbes, se mejorarían las relaciones de cultura y educación.

La conservación y restauración del edificio en cuestión, según la Ley 28296, Ley General del Patrimonio Cultural de la Nación, corresponde legalmente a la Municipalidad de Tumbes. Esta institución es responsable de su deterioro, y debe responder por cualquier evento que altere o destruya parcial o totalmente al monumento. De más está agregar que la concreción de este proyecto de restauración requiere voluntad política. Las iniciativas de preservación de este patrimonio deben gestionarse desde el gobierno local y deben involucrar a los ciudadanos, considerando los porcentajes altos de interés de participación.

Resulta necesario un cambio de visión y de decisión, además de una nueva perspectiva de parte del gobierno local para gestionar e invertir en el Antiguo Cabildo de Tumbes y en otros bienes culturales que alberga la ciudad.

\section{Referencias}

Bodemer, K. (1998). La globalización. Un concepto y sus problemas. Nueva Sociedad, (156), 5471. Recuperado de http://biblioteca.ues.edu.sv/revistas/ 10701666N156-6.pdf.

Casado, I. (2009). Breve historia del concepto de patrimonio histórico: Del monumento al territorio. En Contribuciones a las Ciencias Sociales. Recuperado de www.eumed.net/rev/cccss/06/ icg.htm.

García, P. (2011). El patrimonio cultural: Conceptos básicos. Zaragoza, España: Prensas Universitarias de Zaragoza.

Halbwachs, M. (2004) La memoria colectiva. Zaragoza, España: Prensa Universitaria de Zaragoza.

Hayakawa, J. (2010). Gestión del patrimonio cultural y centros históricos latinoamericanos. Tendiendo puentes entre el patrimonio y la ciudad (1era ed.). Lima, Perú: Universidad Nacional de Ingeniería.

Hayakawa, J. (2015). Gestión del patrimonio cultural y centros históricos latinoamericanos. Tendiendo puentes entre el patrimonio y la ciudad (2da ed.). Lima, Perú: Universidad Nacional de Ingeniería.

Hernández, C. (2017. El 'efecto Alzheimer' en las ciudades. Recuperado de https://www.huffingtonpost.es/carlos-hernandez-pezzi/el-efecto-alzheimer-en-la_b_14431706.html. 
devenir Vol. 6, N¹1, ENERO- JUNIO 2019, PP. 87-106 - ESTUDIOS | ISSN 2312-7562 I E-ISSN 2616-4949

UNIVERSIDAD NACIONAL DE INGENIERÍA, LIMA

doi: https://doi.org/10.21754/devenir.v6i11.635

Instituto Nacional de Cultura. (2015). ¿Qué es patrimonio cultural?. Recuperado de https://www. cultura.gob.pe/sites/default/files/paginternas/ tablaarchivos/04/1manualqueespatrimonio.pdf

Montañez, M. (2016). Gestión y valoración del patrimonio histórico inmueble en el centro histórico del Callao. Devenir, 3(6), 98-124.

Municipalidad Provincial de Tumbes. (2014). Proyecto de Inversión Pública. Restauración y Puesta en Valor del Ex Cabildo de Tumbes-Provincia de Tumbes - Departamento de Tumbes.

Mumford, L. (1938). La cultura de las ciudades. Buenos Aires, Argentina: Emecé.

Peña, J. (1999). Enfermedad del Alzheimer. Del diagnóstico a la terapia: Conceptos y hechos. BarceIona, España: Fundación La Caixa.

Pérez, J. (2016). La suma de pequeñas cosas produce el gran cambio. Recuperado de https:// factorhuma.org/attachments_secure/article/8303/participativa_cast.pdf

Organización de las Naciones Unidas para la Educación, la Ciencia y la Cultura. (2014). Unesco Culture for Development Indicators: Methodology Manual. Recuperado de https://en.unesco. org/creativity/sites/creativity/files/digital-library/CDIS\%20Methodology\%20Manual_0.pdf

Villamón, T. (2017). Reflexiones teóricas contemporáneas sobre patrimonio edificado y su significado. Devenir, 4(8), 123-133. 